\title{
A Study of Gastrointestinal Tract Obstruction in Neonates and Its Management
}

\author{
Prasanta Kumar Tripathy ${ }^{1}$, Laxmikanta Mohapatra ${ }^{2}$, Pradeep Kumar Jena ${ }^{3}$ \\ ${ }^{1}$ Department of Paediatric Surgery, SVPPGIP, SCB Medical College, Cuttack, Odisha, India. \\ ${ }^{2}$ Department of Paediatric Surgery, SVPPGIP, SCB Medical College, Cuttack, Odisha, India. \\ ${ }^{3}$ Department of Paediatric Surgery, SVPPGIP, SCB Medical College, Cuttack, Odisha, India.
}

\section{ABSTRACT}

\section{BACKGROUND}

Gastrointestinal tract obstructions are the most common surgical emergencies in neonatal period. The aetiology of these disorders is diverse and mostly the consequences prenatal developmental malformations. The management and survival are still a challenge, especially in developing countries like India.

\section{METHODS}

A prospective observational study was conducted in a tertiary care paediatric institute from October 2016 to September 2019. Newborns in the age group of one to 28 days, who were operated in the hospital for gastrointestinal tract obstruction were analysed. Institutional Ethics Committee approval was taken. Data with regard to demographic patterns, clinical profile, management approach and outcome, were collected and analysed.

\section{RESULTS}

Out of 531 newborns operated for gastrointestinal obstruction, 80\% cases presented within first week of life. Male neonates were more commonly affected than females (M: F=2.2:1) and 58\% cases were having low birth weight. Anorectal malformation was the commonest cause of obstruction $(40.7 \%$ cases $)$ followed by intestinal atresia (18\% cases). Hirschsprung's disease, malrotation, meconium ileus and hypertrophic pyloric stenosis were among the important aetiologies. The overall mortality in this study was $13 \%$ and septicaemia was the leading cause.

\section{CONCLUSIONS}

Aetiology of gastrointestinal obstruction in newborn is diverse ranging from oesophageal atresia to anorectal malformations. Low birth weight and other comorbidities are associated in many cases. The overall outcome is in improving trend due to gradual understanding about the pathology and advancement of neonatal care. Early diagnosis, surgical intervention and availability of well-equipped neonatal intensive care unit facility are essential for better survival.

\section{KEY WORDS}

Anorectal Malformation, Oesophageal Atresia, Hirschsprung's Disease, Malrotation, Meconium Ileus
Corresponding Author: Dr. Prasanta Kumar Tripathy, Aruonodaya Nagar, Link Road, Cuttack-753012, Odisha, India.

E-mail: drpktripathy555@gmail.com

DOI: $10.14260 / j e m d s / 2020 / 203$

Financial or Other Competing Interests: None.

How to Cite This Article: Tripathy PK, Mohapatra L, Jena PK. A study of gastrointestinal tract obstruction in neonates and its management. J. Evolution Med. Dent. Sci. 2020;9(12):943-948, DOI: $10.14260 / j e m d s / 2020 / 203$

Submission 11-01-2020, Peer Review 29-02-2020, Acceptance 06-03-2020, Published 23-03-2020.

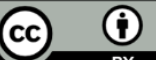




\section{BACKGROUND}

World Health Organization data estimated by Global Burden of Disease study and published in 2019 detected congenital anomalies to account for 17 to $43 \%$ of infant mortality.[1] Congenital anomalies affecting newborn gastrointestinal tract is the most frequent cause of intestinal obstruction. Gastrointestinal obstruction is the commonest surgical emergency in neonatal period i.e. first 28 days of life. [2] The common clinical presentation includes failure to pass meconium, abdominal distension, regurgitation of feeds, vomiting, and visible bowel loops. But, the feature varies according to aetiology, the level and duration of obstruction. The level of obstruction correlates with abdominal distension. Distension is limited to upper abdomen in duodenal and proximal jejunal obstructions. In distal small intestinal or colonic obstructions, generalized abdominal distension is noted. [3] A delay in diagnosis may aggravate abdominal distension causing splinting of diaphragm and respiratory distress. There is always a risk of aspiration pneumonia and severe dehydration, which may subsequently lead to peripheral circulatory failure and metabolic acidosis. Intestinal gangrene and perforation may occur in neonates presenting very late, with resultant peritonitis and septicaemia. The incidence of neonatal surgical emergency is reported as 1-4 per 100 live births. ${ }^{[4]}$ Anorectal malformation, intestinal atresia, Hirschsprung's disease, oesophageal atresia, malrotation and meconium ileus are the usual causes of obstruction in the newborn gastrointestinal tract. [3,4] Typical clinical pictures such as delayed passage of meconium (Hirschsprung's disease) and non-bilious projectile vomiting (infantile hypertrophic pyloric stenosis) makes specific diagnosis in some cases. Difficulty in passing a nasogastric tube into stomach, in a newborn with excessive salivation or frothing from mouth point towards oesophageal atresia with or without tracheo-oesophageal fistula. An obvious external congenital anomaly like absence of anal opening makes a definitive diagnosis in others. Classical radiographic findings are marked in some disease such as double bubble sign in duodenal atresia and gasless abdomen in pure oesophageal atresia.

Neonatal surgery is a challenge in the developing countries and associated with higher mortality rate in comparison to developed western world. In spite of striking improvement in paediatric care, anaesthesia and surgery, the outcome in neonatal surgery is still in a crucial stage. Both the physicians and surgeons have contributing role in the management of these neonates. A well-equipped neonatal surgical intensive care unit, specialized nursing care and facility of total parental nutrition are ideal for survival from these malformations. ${ }^{[3]}$. Although the outcome from gastrointestinal tract obstruction varies from different studies in world, the overall baseline mortality reported in Indian studies is about $20 \% .{ }^{[4]}$ Late presentation to tertiary care hospitals, lack of adequate infrastructure and well equipped neonatal intensive care unit facility contributes to higher mortality. Prematurity, low birth weight and associated congenital malformations adds to this problem. ${ }^{[3,4]}$ Newborn mortality significantly affects the global burden in years of life lost, as deaths occur very early in life. A prospective study on neonatal gastrointestinal tract obstruction is lacking in Indian literature.
The aim of the present study is to find out the clinical profile of neonates with gastrointestinal tract obstruction, their management approach and outcome in our tertiary care hospital.

\section{METHODS}

This prospective observational study was conducted in the Paediatric Surgery department of SVP PG Institute of Paediatrics, SCB Medical College, Cuttack, Odisha from October 2016 to September 2019. Newborns admitted in the hospital for features of obstruction in gastrointestinal tract such as vomiting, regurgitation of feeds, abdominal distension and non-passage of meconium were studied. The study was approved by Institutional Ethics Committee (SCBMC/ OR/IEC/2019/13351). A written informed consent was taken from parents or guardians. Sample size was calculated using Open Epi software (version 3), taking 95\% Confidence interval, $80 \%$ power and the expected change in outcome as $13 \%$ from a baseline of $20 \%{ }^{[4]}$ Data were collected in respect of age, sex, weight at presentation, clinical features, associated anomalies, management approach, complications and survival or mortality.

\section{Inclusion Criteria}

(i) Newborns presenting between 1 to 28 days of life. (ii) Both male and female newborns were included. (iii) Newborns operated for obstruction anywhere in the gastrointestinal tract.

\section{Exclusion Criteria}

(i) Neonates who were detected, but not operated due to severe septicaemia or parental refusal for surgery. (ii) Neonates who were absconded or died before surgery. (iii) Neonates in whom a definite diagnosis or aetiology was not reached during the study period.

\section{Initial Resuscitation and Surgical Management}

All newborns were kept warm and nil orally. They were stabilized with oxygen inhalation, intravenous fluids and antibiotics. Routine investigations like hemogram, serum electrolytes and urea/creatinine were done. Erect abdominal X-ray including chest was done in all cases and ultrasonography of abdomen was done in selected cases such as pyloric stenosis and malrotation. Cross table prone lateral radiography (CTPL) was done in anorectal malformation (ARM) cases to determine the position of rectal gas shadow. Colostomy was planned in high ARM cases and anoplasty in low ARM cases. The newborns were operated after correction of dehydration and serum electrolyte imbalance. All excised tissue and biopsy samples were sent for histopathological study. Postoperative care continued with oxygen inhalation, nasogastric decompression, intravenous fluids and antibiotics. Sick newborns were transferred to the neonatal intensive care unit. The patients were discharged only after full feeds and with follow up advice like colostomy care. The operative findings and procedure, morbidity and mortality were recorded. They were followed for a minimum period of 3 to 6 months. The final outcome was recorded in terms of postoperative complications and survival. 


\section{Statistical Analysis}

Statistical analysis was done in Microsoft Excel using QI Macros software. The gender distribution in different aetiology was depicted as a bar diagram. The number of cases with varied aetiology was presented as percentage (\%). Fisher exact test was used to calculate probability of events. A value of $p<0.05$ was taken as significant.

\section{RESULTS}

\begin{tabular}{|c|c|c|c|c|c|c|c|c|}
\hline z & $\frac{\overrightarrow{00}}{\frac{0}{0}}$ & 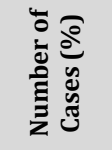 & 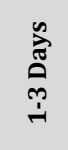 & $\begin{array}{l}\stackrel{n}{\vec{\sigma}} \\
\stackrel{0}{\mathfrak{d}} \\
\dot{d}\end{array}$ & 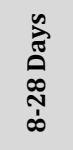 & $\begin{array}{l}60 \\
\text { In } \\
\text { in } \\
v\end{array}$ & 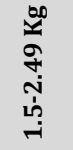 & $\begin{array}{l}80 \\
1 \\
10 \\
\text { N } \\
\Lambda 1\end{array}$ \\
\hline 1 & EA with or without TEF & $89(16.8)$ & 51 & 30 & 8 & 2 & 67 & 21 \\
\hline 2 & IHPS & $27(5.1)$ & - & - & 27 & - & 3 & 24 \\
\hline 3 & Intestinal Atresia & $96(18.1)$ & 42 & 28 & 26 & 8 & 70 & 18 \\
\hline 4 & Duplication cyst & $1(0.2)$ & 1 & - & - & - & 1 & - \\
\hline 5 & Malrotation & $22(4.1)$ & & 8 & 14 & & 11 & 11 \\
\hline 6 & MI & $16(3.0)$ & 7 & 7 & 2 & 1 & 8 & 7 \\
\hline 7 & Herniation Umbilical cord & $5(0.9)$ & 4 & 1 & & & 3 & 2 \\
\hline 8 & HD & $55(10.4)$ & 18 & 19 & 18 & - & 29 & 26 \\
\hline 9 & NEC & $4(0.7)$ & - & 1 & 3 & 2 & 2 & - \\
\hline 10 & High ARM & $184(34.7)$ & 158 & 22 & 4 & 4 & 83 & 87 \\
\hline \multirow[t]{2}{*}{11} & Low ARM & $32(6.0)$ & 24 & 5 & 3 & & 17 & 15 \\
\hline & Total & $\begin{array}{c}531 \\
(100)\end{array}$ & $\begin{array}{c}305 \\
(57 \%) \\
\end{array}$ & $\begin{array}{c}121 \\
(23 \%)\end{array}$ & $\begin{array}{c}105 \\
(20 \%)\end{array}$ & $\begin{array}{c}16 \\
(3 \%)\end{array}$ & $\begin{array}{c}294 \\
(55 \%)\end{array}$ & $\begin{array}{c}221 \\
(42 \%)\end{array}$ \\
\hline & Table 1. Age a & Veight & the $T$ & ime of & fPrese & ntati & & \\
\hline
\end{tabular}

\begin{tabular}{|c|c|c|c|}
\hline & Surgical Procedure & Pathology & $\begin{array}{l}\text { Number of } \\
\text { Cases (\%) }\end{array}$ \\
\hline 1 & $\begin{array}{l}\text { Thoracotomy, ligation of fistula } \\
\text { and end to end anastomosis }\end{array}$ & EA with TEF & $79(15)$ \\
\hline 2 & $\begin{array}{l}\text { Oesophagostomy and } \\
\text { Gastrostomy }\end{array}$ & $\begin{array}{c}\text { Pure EA (7), Long gap EA with } \\
\text { TEF (3) }\end{array}$ & $10(1.9)$ \\
\hline 3 & Ramstedt's pyloromyotomy & Pyloric stenosis & $27(5)$ \\
\hline 4 & Resection and anastomosis & $\begin{array}{c}\text { Intestinal atresia (60), } \\
\text { MR with volvulus (4), } \\
\text { Herniation of umbilical cord (2), } \\
\text { NEC (4), Duplication cyst (1) }\end{array}$ & $71(13)$ \\
\hline 5 & $\begin{array}{l}\text { Excision of web and closure } \\
\text { of enterotomy }\end{array}$ & Type I intestinal atresia & $20(3.8)$ \\
\hline 6 & Duodeno-Duodenostomy & DA & $16(3)$ \\
\hline 7 & Ladd's Procedure & MR & $24(4.5)$ \\
\hline 8 & Colostomy & High ARM and HD & $242(46)$ \\
\hline 9 & Anoplasty & Low ARM & $32(6)$ \\
\hline 10 & Laparotomy and repair & Herniation of Umbilical Cord & $3(0.5)$ \\
\hline \multicolumn{4}{|c|}{ Table 2. Neonatal Operative Procedures } \\
\hline
\end{tabular}

\begin{tabular}{|c|c|c|c|c|c|}
\hline $\begin{array}{c}\text { Aetiology } \\
\text { (No. of Cases) }\end{array}$ & $\begin{array}{l}\text { Complications } \\
\text { (No. of Cases) }\end{array}$ & $\mathbf{p}^{*}$ & $\begin{array}{c}\text { Survival } \\
\text { (No. of } \\
\text { Cases) }\end{array}$ & Mortality & p\# \\
\hline $\mathrm{EA}(89)$ & $\begin{array}{c}\text { Anastomotic Leak } \\
\text { Septicaemia(35) } \\
\text { Pneumonia }\end{array}$ & $0.00006^{* *}$ & 69 & $20(22 \%)$ & $0.02^{* *}$ \\
\hline High ARM (184) & $\begin{array}{c}\text { Septicaemia, colostomy } \\
\text { complications, } \\
\text { Redo Colostomy (31) }\end{array}$ & 0.47 & 166 & $18(10 \%)$ & 0.29 \\
\hline Low ARM (32) & - & - & 32 & 0 & - \\
\hline $\begin{array}{c}\text { Intestinal Atresia } \\
\text { (96) }\end{array}$ & $\begin{array}{c}\text { Anastomotic Leak, } \\
\text { Septicaemia (20) }\end{array}$ & 0.88 & 78 & $18(19 \%)$ & 0.14 \\
\hline IHPS (27) & $\begin{array}{l}\text { Redo pyloromyotomy } \\
\text { (1) }\end{array}$ & 0.07 & 27 & - & 0.06 \\
\hline HD (55) & $\begin{array}{c}\text { Colostomy } \\
\text { Complications, } \\
\text { Redo colostomy (6) }\end{array}$ & 0.16 & 52 & $3(5 \%)$ & 0.13 \\
\hline Malrotation (22) & $\begin{array}{l}\text { Wound dehiscence and } \\
\text { redo- laparotomy (4) }\end{array}$ & 0.91 & 19 & $3(14 \%)$ & 0.75 \\
\hline $\operatorname{MI}(16)$ & $\begin{array}{l}\text { Septicaemia and } \\
\text { Re-laparotomy (4) }\end{array}$ & 0.82 & 16 & $3(19 \%)$ & 0.72 \\
\hline $\begin{array}{l}\text { Herniation of } \\
\text { Umbilical } \\
\text { cord (5) }\end{array}$ & Septicaemia (1) & 0.58 & 4 & $1(20 \%)$ & 0.49 \\
\hline $\operatorname{NEC}(4)$ & Septicaemia (2) & 0.37 & 3 & $1(25 \%)$ & 0.42 \\
\hline Duplication Cyst (1) & - & - & 1 & 0 & - \\
\hline Total (531) & $104(20 \%)$ & 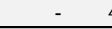 & $463(87 \%)$ & $68(13 \%)$ & - \\
\hline \multicolumn{6}{|c|}{ Table 3. Outcome in Cases of GIT Obstruction } \\
\hline
\end{tabular}

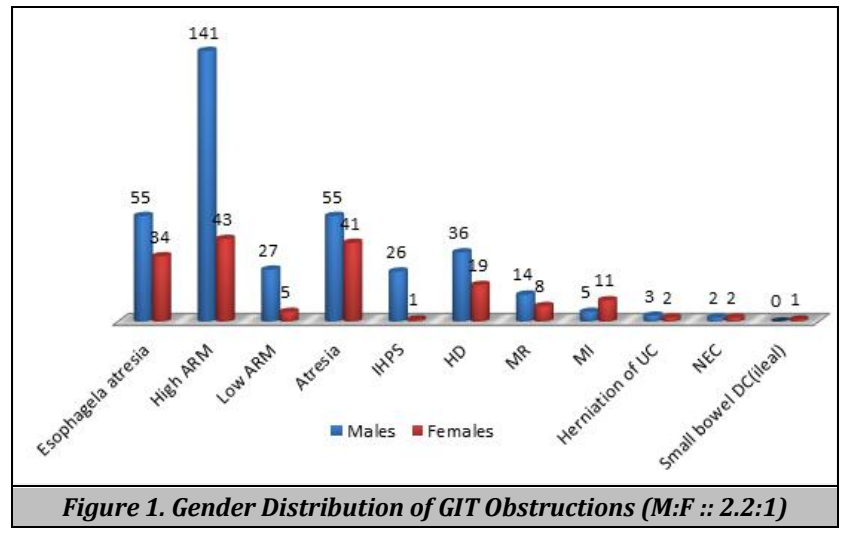

A total of 531 newborns were operated for gastrointestinal tract (GIT) obstruction during the 3-year study period. Male neonates $(n=364)$ outnumbered female neonates $(n=167)$ giving a M: F ratio of 2.2:1 (fig. 1). Majority of the newborns presented to us during first week of life (80\% cases), especially within first 3 days (table No-1). Fifty eight percent of neonates were of low birth weight and $3 \%$ were very low birth weight. Anorectal malformation was the commonest cause of obstruction. The spectrum of ARM varies from simple perineal fistulas to complex pouch colon and cloacal anomalies along with involvement of genitor-urinary tract. High ARM cases were more commonly encountered, including 17 cases of congenital pouch colon 12 cases of cloacal anomaly and 2 cases of rectal atresia. Absence of anal opening, non-passage of meconium and abdominal distension were the presenting features. These cases were associated with other congenital anomalies like oesophageal atresia (3 cases), intestinal atresia (3 cases), Down syndrome (3 cases), congenital talipes equinovarus (CTEV) deformity in 2 cases and lumbosacral meningomyelocele in one case. The colostomy was done in all cases of high ARM but, it required revision in 7 cases due to stoma related complications.

Intestinal atresia was the second most common cause of GIT obstruction in neonates and duodenum was the commonest site of atresia. Bilious vomiting, abdominal distension and visible bowel loops were common presenting features. A double bubble appearance in plain X-ray abdomen was suggestive of duodenal atresia (DA). DA cases were associated with Down syndrome in 5 cases and ARM in 2 cases. Both the cases of pyloric atresia were associated with epidermolysis bullosa. Colonic atresia patients were associated with gastroschisis ( 2 cases), malrotation ( 2 cases) and ARM (one case). oesophageal atresia (EA) with or without tracheo-oesophageal fistula (TEF) was the third most cause of obstruction. Regurgitation of feeds, excessive salivation and respiratory distress were the principal modes of presentation. Diagnosis was made by inability to pass $10 \mathrm{fr}$ firm red rubber tube from mouth into stomach. X-ray shows tip of nasogastric tube in proximal oesophageal pouch or coiling. Additional finding of gas-less abdomen points towards pure EA, i.e. without TEF. Right side thoracotomy, ligation of fistula and end-to-end anastomosis was the standard operative procedure in EA with TEF. Oesophagostomy and gastrostomy was performed in long gap cases and in cases with pure EA.

Nonbilious, projectile vomiting, dehydration and finding of a pyloric lump was presenting feature in idiopathic 
hypertrophic pyloric stenosis (IHPS). All the cases presented in $3^{\text {rd }}$ and $4^{\text {th }}$ week of life with a gross male predominance. Ultrasonography revealed pyloric channel length $\geq 12 \mathrm{~mm}$ and muscle thickness $\geq 3 \mathrm{~mm}$ in these cases. Dehydration and electrolyte imbalance were corrected before Ramstedt's pyloromyotomy. Delayed passage of meconium, abdominal distension and visible bowel loops were presenting features of Hirschsprung's disease (HD). Laparotomy, multiple levelling biopsy and colostomy was done in these cases. Classical rectosigmoid disease was found in 45 cases and sigmoid colostomy was done in these neonates. Transverse loop colostomy was done in cases where the transition zone was located more proximally. Ladd procedure consisting of evisceration of intestine, counter clockwise derotation of volvulus, division of Ladd peritoneal bands and appendicectomy was done in most of the cases of malrotation. Bowel resection and anastomosis was required in 4 cases with gangrene of intestine due to volvulus. Cases of necrotizing enterocolitis (NEC) also required bowel resection and anastomosis due to gangrene.

A diverting colostomy, usually in left lower abdomen was the most common surgical procedure performed in $46 \%$ cases followed by thoracotomy for EA with TEF (15\%) and bowel resection with anastomosis in $13 \%$ cases (table 2). Postoperative complications like septicaemia, pneumonia, anastomotic leak and colostomy related complications were reported in $20 \%$ cases. However, the complications were more significantly noted in EA cases $(\mathrm{p}=0.00006)$. The overall mortality in this study was $13 \%$ and septicaemia was the leading cause (table 3). A significantly higher mortality was noted in EA and TEF cases $(p=0.02)$ due to associated pneumonia, septicaemia and other co-morbidities.

\section{DISCUSSION}

Gastrointestinal tract obstruction is the leading surgical emergency in neonates and is particularly challenging in developing countries like India. It occurs in approximately 1 in 1500 live births and the spectrum is diverse varying from embryonal malformations to some undiscovered aetiology. ${ }^{[5]}$ The male to female ratio in the present study was 2.2:1, which may be due to the fact that, more number of male newborns were being presented to our hospital during the study period or more males are affected in this disorder. Similar gender ratio was also reported in other studies.[6,7] Diseases like IHPS have an inherent gross male predominance. Fifty eight percent of patients were in low birth weight group, a finding which is also noted in other series. [4]

Anorectal malformation was found to be the most common cause of GIT obstruction in this series accounting for $40.7 \%$ of the cases. This anomaly was reported between 35.6 to $48 \%$ of cases in different series. ${ }^{[3,4,8]}$ So our findings are similar to these series. However, Ameh et al from Nigeria found a much higher incidence (68.9\% of cases). This may be partly due to non-inclusion of oesophageal atresia, a major contributing aetiology in their series.[9]Traditionally, ARMs are categorized as high or low types, depending on the position of distal end of rectum in relation to the puborectalis sling. When the rectum ends above the puborectalis sling, it is called high anomaly.[2,10] High anomalies are more commonly reported than low anomalies. This malformation was managed in staged approach in our institution, which is a standard protocol. Initial diverting colostomy was done and definitive surgery, i.e. posterior sagittal anorectoplasty is planned at a later stage. Unlike low ARMs, High ARMs were associated with other co-morbidities like EA, DA, Down syndrome and CTEV as in other studies [3,9] and a resultant higher mortality. Low ARMs were managed by anoplasty and none of these patients died during the study period. In congenital pouch colon, a part or entire colon exhibit pouchlike dilatation along with fistulous communication to the urogenital system. This anomaly has an unique geographical distribution in world and majority of these cases were reported from northern and western part of India.[11] Detection of 17 cases of congenital pouch colon within a period of 3 years in our hospital, located in eastern part of India is a remarkable feature.

Intestinal atresia was found to be the second most common cause of GIT obstruction, accounting for $18 \%$ of cases in this series. Intestinal atresia is also reported in 13.7 to $23 \%$ of cases in different series. ${ }^{[3,8,12]}$ However, studies by Ameh et al (6.7\%) and Seth et al (12\%) report lower incidences. ${ }^{[4,9]}$ Two cases of congenital pyloric atresia (CPA) were operated and managed during the study period. CPAs are rare conditions and commonly occur as an isolated anomaly, with good outcome.[13] However, Epidermolysis bullosa (EB), a hereditary disorder manifesting as blistering lesions on skin are often associated and the association is described as Carmi's syndrome. [14] Both the cases of CPA in our series had associated EB and one neonate died postoperatively. Carmi's syndrome is a very rare malformation, having mutations in integrin gene with resultant poor prognosis.[13,15] In this study, DA was not only the most common type of small bowel atresia, but also associated with higher incidences of other anomalies like Down syndrome (5 cases), malrotation ( 2 cases) and ARM(2 cases). The developmental disorder behind DA is 'failure of recanalization' which occur between 9 to 11 weeks of embryonic life. [2,16]This is an early event, when other organs are developing with resultant, increased incidence of other malformations. In contrast, the embryological disorder causing most distal jejunoileal atresias, is 'vascular accident' occurring late in the intrauterine life and by that time other organs are already developed. One case of Apple-peel variety of jejunal atresia in the present study had a rare coexistence with isolated duplication cyst. ${ }^{[17]}$ Although, colon is an unusual location for atresia, 12 cases of colonic atresia were detected and managed during study period. One of these cases had high ARM without fistula, as an association and this coexistence is rarely reported in literature.[18]

Oesophageal atresia is not included in some studies on intestinal obstruction, due to an explanation that, the presentation of this anomaly differs from other causes.[12,16] But, anatomically and functionally, alimentary tract extends from mouth to anus. So, we have included these important anomalies in our study and found in $16.8 \%$ of cases. Seth et al also found EA in $8 \%$ of their cases.[4]EA was associated with other anomalies like ARM and DA in $10 \%$ of our cases. This VACTERL association is also well documented in literature.[7,10] Although, EA is mostly associated with TEF, EA without TEF (pure EA) is reported in 6\% cases.[19] Similar 
figures were detected in our study ( $7.8 \%$ cases) and unlike TEF, thoracotomy was not performed in these cases. Oesophagostomy and gastrostomy were done as initial procedure during neonatal period and planned for oesophageal replacement at a later stage. This staged procedure is widely accepted and described by

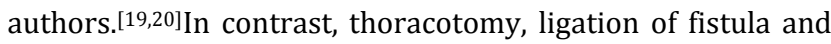
end to end anastomosis was done in EA with TEF cases as single stage surgery. In neonates with long gap EA and TEF (3 cases), ligation of fistula, oesophagostomy and gastrostomy was performed, as two oesophageal ends could not be brought together in order to perform a tension free anastomosis.

Hirschsprung's disease is a developmental disorder affecting enteric nervous system, resulting in absence of ganglion cells in the distal bowel. During embryonic life neural cell migration occurs in a cranio-caudal fashion in GIT and therefore, rectum and sigmoid colon (classical HD) are mostly affected.[10]HD was encountered in $10 \%$ of cases in this study, which is similar to studies reporting between 7.3 to $13 \%$ incidences. $[4,7,8,9]$ However, studies by Pathak et al and Saha et al found higher incidences of $17 \%$ and $22.93 \%$ respectively. [3,16]This disparity is due to non-inclusion of EA and/or ARM cases, causing relatively higher incidence of HD in their series. Delayed passage of meconium was almost a constant feature in these newborns, in addition to other presentations of intestinal obstruction. During laparotomy dilated proximal bowel, narrow distal bowel and typical transition zone in between was detected. A two staged surgical approach is followed in our institute. Laparotomy, multiple levelling biopsy and colostomy (usually in sigmoid colon) is performed during neonatal period. After confirming the diagnosis by histopathological study, the definitive procedure (usually Soave's endorectal pull through) is performed around 6 months of age. IHPS was detected in $5.1 \%$ of our cases, which corroborates with findings from other studies.[8,9,12] A gross male predominance was also noted in our series like the above studies. All the neonates presented during $3^{\text {rd }}$ and $4^{\text {th }}$ week of life, which is the trend in this disorder.[10] None of these neonates died postoperatively in our study.

Although intestinal malrotation may present later in childhood and even in adulthood, more than $75 \%$ cases present during neonatal period.[10] Bilious vomiting is the cardinal manifestation of this disorder. Initially the abdomen is scaphoid in nature but, may exhibit progressive distension due to midgut volvulus. Ultrasonography reveals reversal of superior artery and vein relationship and the whirlpool sign on colour Doppler.[10,21] Incidence of malrotation in our series (4.1\%) corroborates with the study by Ameh et al.[9] The relative higher incidence of malrotation found in other studies may be due to exclusion of diseases like ARM, EA and IHPS in their series. ${ }^{[3,6,7,8]}$ Meconium ileus (MI) is caused by accumulation of inspissated meconium in bowel lumen causing obstruction. The disease is usually associated with cystic fibrosis (CF) and MI is the earliest manifestation of CF. However, only $15 \%$ of newborns with CF present as MI.[1,10] The $3 \%$ incidence of this disease in our series is in comparison to other studies, which report 4 to $7 \%$ incidences. ${ }^{[3,7,12]}$ But, studies by Rao et al and Saha et al detected 11 and $18 \%$ cases.[3,6] But, Ameh et al found only
$0.7 \%$ incidence of $\mathrm{MI}$ in his study.[9] One important feature noted in this disorder is that; in spite of dilated intestinal loops, plain X-rays were not showing air-fluid levels, due to thick and viscid intraluminal meconium.

The mortality from GIT obstruction in developing countries is reported between 16 to $26 \%$ cases.[3,6,7,9]The overall mortality in our study was found to be $13 \%$. This reduction in mortality rates in recent years reflects increasing knowledge about the disease spectrum, early referral of newborns from periphery to tertiary care hospitals and improvement in the neonatal care. Although, septicaemia is the leading cause of mortality, low birth weight, pneumonia and other associated congenital malformations contributes towards morbidity and mortality.

\section{Limitations}

A group of disorders such as anorectal malformation, Hirschsprung's disease and pure oesophageal atresia require staged surgical approach. In this study, only the first stage surgery done during neonatal period was analysed. The management and outcome during subsequent surgery is beyond the scope of the present study.

\section{CONCLUSIONS}

Our study showed that, anorectal malformation was the most common cause of GIT obstruction during neonatal period. It is followed by intestinal atresia and oesophageal atresia. The initial 3 days of life is crucial as majority of patients presented during that period. Male newborns were more commonly affected or referred to us than female newborns. Majority of neonates were of low birth weight, a risk factor for survival. However, the overall survival rate of $87 \%$ in the present study is a reflection of gradual advancement in neonatal care, surgery and anaesthesia. But, the key areas of improvement seen are improved awareness and recognition of the disease spectrum, timely referral from rural hospitals, early resuscitation of these tiny newborns and optimal utilization of advanced neonatal supporting systems.

\section{REFERENCES}

[1] Boyle B, Addor MC, Arriola L, et al. Estimating global burden of disease due to congenital anomaly: an analysis of European data. Arch Dis Child Fetal Neonatal Ed 2018;103(1):F22-F8.

[2] Vinocur DN, Lee EY, Eisenberg RL. Neonatal intestinal obstruction. Am J Roentgenol 2012;198(1):W1-W10.

[3] Saha AK, Ali MB, Biswas SK, et al. Neonatal intestinal obstruction: patterns, problems and outcome. Bang Med J (Khulna) 2012;45:6-10.

[4] Seth A, Chanchlani R, Rakhonde AK. Neonatal gastrointestinal emergencies in a tertiary care center in Bhopal, India: a prospective study. IJSS Journal of Surgery 2015;1(5):1-4.

[5] Wyllie R. Intestinal atresia, stenosis and malrotation. In: Kliegman RM, Behrman RE, Jenson HB, eds. Nelson's text 
book of Pediatrics. Vol. 2. 18 th edn. Philadelphia: Saunders/Elsevier 2008: p 1558-62.

[6] Rao LD, Rao KVJ, Kameswari K. Neonatal intestinal obstruction. IOSR-JDMS 2018;17(2):50-3.

[7] Verma A, Rattan KN, Yadav R. Neonatal intestinal obstruction: a 15 year experience in a tertiary care hospital. J Clin Diagn Res 2016;10(2):SC10-SC3.

[8] Talari VK, Sipala SK. A clinical study of neonatal intestinal obstruction. IOSR-JDMS 2017;16(8):8-14. DOI: 10.9790/0853- 1608030814.

[9] Ameh EA, Chirdan LB. Neonatal intestinal obstruction in Zaria, Nigeria. East Afr Med J 2000;77(9):510-3.

[10] Desoky SM, Kylat RI, Udayasankar U, et al. Managing neonatal bowel obstruction: clinical perspectives. RRN 2018;8:19-32.

[11] Mathur P, Medicheria KM, Chaudhary S, et al. Whole exome sequencing reveals rare variants linked to congenital pouch colon. Scientific Reports 2018;8(1):6646.

[12] Agarwal N, Agarwal D, Pathak D, et al. Patterns and surgical outcome of neonatal small bowel obstruction: a single centre experience from Ujjain, India. Int Surg J 2019;6(12):4471-5.

[13] Bawazir OA, Al-Salem AH. Congenital pyloric atresia: clinical features, diagnosis, associated anomalies, management and outcome. Ann Pediatr Surg 2017;13(4):188-93.

DOI:
[14] Carmi R, Sofer S, Karphus M, et al. Aplasia cutis congenital in two sibs discordant for pyloric atresia. Am J Med Gent 1982;11(3):319-28.

[15] Gupta R, Soni V, Mathur P, et al. Congenital pyloric atresia and associated anomalies: a case series. J Neonat Surg 2013;2(4):40.

[16] Pathak M, Saxena R, Sinha A, et al. Hirschsprung's disease and neonatal intestinal obstruction: Where does it lie in the spectrum? J Clin Neonatol 2018;7(4):231-6. DOI:10.4103/jcn.JCN_48_18.

[17] Tripathy PK, Pattnaik K, Jena PK, et al. Apple-peel intestinal atresia along with isolated Jejunal duplication cyst in a newborn - an extremely rare case report and brief review. J Clin Diagn Res 2017;11(6):SD01-02.

[18] Tripathy PK, Jena PK. Type II colonic atresia and high anorectal malformation: a rare coexistence and literature review. Indian J Neonatal Med and Res 2017;5(3):PC04-PC06.

DOI: 10.7860/IJNMR/2017/29190.2213.

[19] Harman CM, Coran AG. Congenital anomalies of the esophagus. In: Coran AG, Adzick NS, Krummel TM, et al. eds. Pediatric Surgery. $7^{\text {th }}$ edn. Saunders/Elseiver 2012: p. 893-918.

[20] Tripathy PK, Rao KLN, Chowdhary SK, et al. Lower pouch mobilization in long gap oesophageal atresia. J Ind Assoc Ped Surg 2004;9(4):172-8.

[21] Zhang W, Sun H, Luo F. The efficiency of sonography in diagnosing volvulus in neonates with suspected intestinal malrotation. Medicine (Baltimore) 2017;96(42):e8287. 